\title{
Conserso | Protocolo Brasileiro para Infecções Sexualmente Transmissíveis 2020: infecções que causam corrimento vaginal
}

doi: 10.1590/S1679-4974202100007.esp1

\author{
Brazilian Protocol for Sexually Transmitted Infections 2020: infections causing \\ vaginal discharge
}

\section{Protocolo Brasileño para Infecciones de Transmisión Sexual 2020: infecciones que causan flujo vaginal}

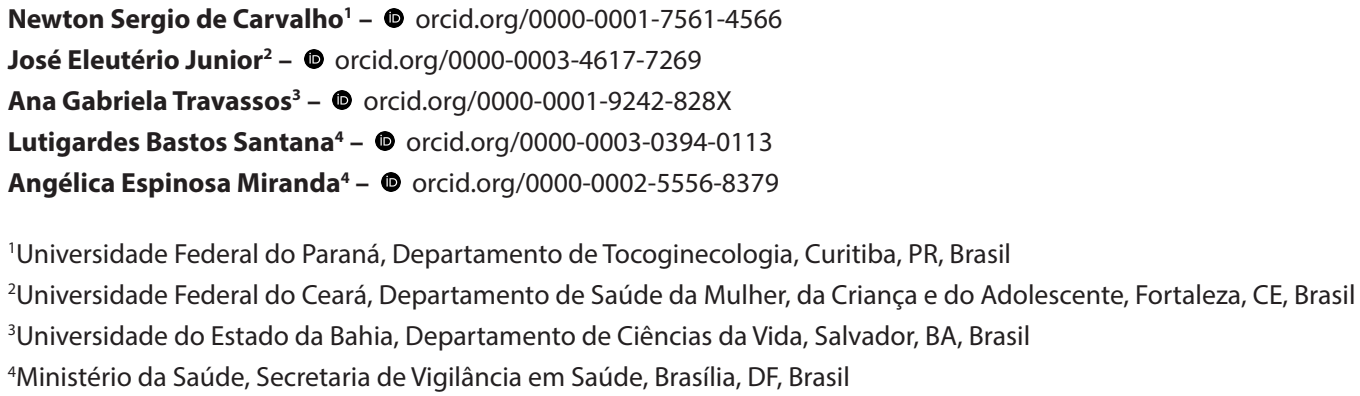

\section{Resumo}

0 tema corrimento vaginal é um dos capítulos que compõem o Protocolo Clínico e Diretrizes Terapêuticas para Atenção Integral às Pessoas com Infecções Sexualmente Transmissíveis, publicado pelo Ministério da Saúde do Brasil em 2020. Tal documento foi elaborado com base em evidências científicas e validado em discussões com especialistas. Neste artigo, são apresentados aspectos epidemiológicos e clínicos relacionados às situações de corrimento vaginal, bem como orientações aos gestores e profissionais de saúde na triagem, diagnóstico e tratamento desses agravos, que constituem uma das principais queixas entre mulheres que procuram serviços de saúde e que podem ser causados por fatores infecciosos ou não infecciosos. Além disso, são apresentadas informações sobre estratégias para as ações de vigilância, prevenção e controle, a fim de promover o conhecimento do problema e a oferta de assistência de qualidade e tratamento efetivo.

Palavras-chave: Vaginite; Candidíase Vulvovaginal; Vaginose Bacteriana; Tricomoníase; Doenças Sexualmente Transmissíveis.

Endereço para correspondência:

Angélica Espinosa Miranda - Ministério da Saúde, Secretaria de Vigilância em Saúde, SRTVN, Quadra 701, Via W 5 Norte, Lote D, Edifício PO 700, Brasília, DF, Brasil. CEP: 70719-040

E-mail: angelica.miranda@aufes.br 


\section{Apresentação}

0 presente artigo está relacionado ao capítulo sobre infecções que causam corrimento vaginal do Protocolo Clínico e Diretrizes Terapêuticas (PCDT) para Atenção Integral às Pessoas com Infecções Sexualmente Transmissíveis (IST), publicado pela Secretaria de Vigilância em Saúde, do Ministério da Saúde do Brasil. Para a elaboração do PCDT, são realizadas a seleção e a análise das evidências disponíveis na literatura e a discussão em um painel de especialistas. 0 documento foi aprovado pela Comissão Nacional de Incorporação de Tecnologias no Sistema Único de Saúde (Conitec) e atualizado pelo grupo de especialistas em IST em 2020. ${ }^{1}$

\section{Em serviços que atendem casos de infecções sexualmente transmissíveis, 0 corrimento vaginal é o principal sintoma referido, sendo também frequente entre gestantes.}

\section{Aspectos epidemiológicos}

Em serviços que atendem casos de IST, o corrimento vaginal é 0 principal sintoma referido, ${ }^{2-4}$ sendo também frequente entre gestantes. ${ }^{5-7}$ Entre as causas não infecciosas do problema, incluem-se aumento excessivo da eliminação de material mucoide fisiológico, presença de corpo estranho intravaginal e vaginite atrófica, a qual pode ocorrer em mulheres na pós-menopausa, durante a amamentação ou como efeito de radioterapia local em tratamento oncológico. ${ }^{4,7,8}$ Outras situações podem causar prurido vulvovaginal sem corrimento, como dermatites alérgicas ou irritativas (sabonetes, perfumes e látex) ou doenças de pele (dermatite atópica, líquen e psoríase). ${ }^{8}$

Entre as causas infecciosas do corrimento vaginal, a mulher pode apresentar, simultaneamente, infecção por mais de um agente etiológico, o que ocasiona corrimento de aspecto inespecífico. ${ }^{4}$ Os agentes podem se associar com vaginite ou vaginose, a depender $\mathrm{da}$ existência ou não de processo inflamatório. Trata-se de afecções do epitélio estratificado da vulva e vagina, cujos agentes etiológicos mais frequentes são fungos, principalmente Candida albicans; bactérias anaeróbicas associadas a vaginose bacteriana; e o protozoário
Trichomonas vaginalis. Além disso, ainda pode haver vaginose citolítica, disbiose decorrente do grande crescimento de lactobacilos e da ação lítica sobre as células escamosas, ${ }^{4,9}$ além da possibilidade de ocorrência de vaginites mistas.

C. albicans é o agente etiológico da candidíase vulvovaginal em $80 \%$ a $92 \%$ dos casos; as espécies não albicans (Candida glabrata, Candida tropicalis, Candida krusei, Candida parapsilosis) e Saccharomyces cerevisae são menos prevalentes. ${ }^{9}$ Durante a vida reprodutiva, $10 \%$ a $20 \%$ das mulheres serão colonizadas por Candida sp. de forma assintomática, sem requerer tratamento, uma vez que a levedura pode fazer parte do meio ambiente vaginal..$^{10,11}$ Dentre os fatores que predispõem à candidíase vulvovaginal, destacam-se os indicados na Figura 1. A candidíase vulvovaginal classifica-se em não complicada e complicada. A primeira ocorre quando todos os critérios a seguir estão presentes: sintomas leves/moderados e de frequência esporádica; $C$. albicans como agente etiológico; e ausência de comorbidades. A candidíase vulvovaginal complicada ocorre quando pelo menos um dos seguintes critérios estão presentes: sintomas intensos; recorrência de quatro ou mais episódios ao ano; agente etiológico não albicans $(C$. glabrata, C. kruzei); presença de comorbidades como diabetes e infecção pelo vírus da imunodeficiência humana (buman immunodeficiency virus, HIV); ou gestação., ${ }^{4,11} \mathrm{~A}$ maioria das candidíases vulvovaginais não são complicadas e respondem a vários esquemas terapêuticos. Todavia, observa-se a instalação da forma recorrente do agravo em $5 \%$ das mulheres. ${ }^{11,12}$

A vaginose bacteriana é a desordem mais frequente do trato genital inferior entre mulheres em idade reprodutiva e a causa mais prevalente de corrimento vaginal, sendo frequente se apresentar com odor fétido. Está associada à redução de lactobacilos e ao crescimento de inúmeras bactérias anaeróbias e facultativas, como bacilos curtos Gram variáveis, bacilos curvos Gram-negativos e cocos Gram-negativos anaeróbicos, com variação individual, principalmente, de Gardnerella,Atopobium, Prevotella, Megasphaera, Leptotrichia, Sneathia, Bifidobacterium, Dialister, Mobiluncus, Ureaplasma, Mycoplasma e três espécies de Clostridium conhecidas como bactérias associadas à vaginose bacteriana (bacterial vaginosis associated bacteria, BVAB 1 a 3). ${ }^{13}$ Determinadas alterações do microbioma vaginal (disbiose) podem se 


\begin{tabular}{|l|}
\hline Gravidez \\
\hline Obesidade \\
\hline Diabetes mellitus (descompensado) \\
\hline Uso de corticoides \\
\hline Uso de antibióticos \\
\hline Uso de contraceptivos orais \\
\hline Uso de imunossupressores ou quimio/radioterapia \\
\hline Alterações na resposta imunológica (imunodeficiência) \\
\hline Hábitos de higiene e vestuário que aumentem a umidade e o calor local \\
\hline Contato com substâncias alergênicas e irritantes (ex.: talcos, perfumes, sabonetes ou desodorantes íntimos) \\
\hline Infecção pelo HIV \\
\hline
\end{tabular}

Fonte: adaptado do Protocolo Clínico e Diretrizes Terapêuticas para Atenção Integral às Pessoas com Infecçōes Sexualmente Transmissíveis, 2020.22.

\section{Figura 1 - Fatores que predispõem à candidíase vulvovaginal}

associar à maior prevalência da vaginose bacteriana. Estudo sobre as características do microbioma de mulheres brasileiras em idade reprodutiva revelou 0 tipo de microbioma (community-statetypes, CST) correspondente a CST IV, com depleção de lactobacilos e aumento do $\mathrm{pH}$ vaginal em $27,4 \%$, estando a vaginose bacteriana presente em $79,6 \%$ dos casos. ${ }^{14}$

A tricomoníase é a IST não viral mais comum, a qual acomete cerca de 140 milhões de pessoas ao ano no mundo. É causada por um parasita flagelado, T. vaginalis,${ }^{15}$ que acarreta mudança no microbioma vaginal, aumento da resposta inflamatória local e redução importante no número de Lactobacillus sp. A tricomoníase está associada ao aumento da probabilidade de transmissão do HIV. ${ }^{16}$

Em algumas ocasiões, ocorre crescimento excessivo de lactobacilos, com grande destruição de células escamosas intermediárias (citólise), associado a sintomas irritativos genitais ${ }^{17}$. Trata-se de vaginose citolítica, um quadro normalmente cíclico em mulheres em idade reprodutiva ${ }^{16}$, com prevalência de $1 \%$ a $7 \%$, mais frequente entre 25 e 40 anos. ${ }^{17,18}$

Vaginites mistas são situações em que há presença de dois patógenos que causam os sintomas vulvovaginais. Podem ser patógenos com predileção por $\mathrm{pH}$ vaginal idêntico ou não. Pode haver, por exemplo, vaginite por T. vaginalis associada à vaginose bacteriana. ${ }^{19}$ No entanto, a forma mais frequente de vaginite mista é a associação de infecção por Candida com vaginose bacteriana. A sua frequência varia entre $7 \%$ e $22 \%$ dos quadros de corrimentos vaginais, a depender do método diagnóstico utilizado. ${ }^{20}$

\section{Aspectos clínicos}

A infecção e a disbiose vaginal podem estar associadas com um ou mais sintomas de variadas formas de corrimento, prurido, irritação e odor. ${ }^{21}$ Por isso, é importante sempre identificar, na anamnese, aspectos relacionados à consistência, cor e alterações do corrimento, além da presença de prurido e irritação local e de odor. A investigação da história clínica deve ser minuciosa, abrangendo informações sobre comportamentos e práticas sexuais, data da última menstruação para avaliar a fase do ciclo menstrual, práticas de higiene vaginal e uso de medicamentos tópicos ou sistêmicos e outros potenciais agentes irritantes locais, além de comorbidades como diabetes e infecção pelo HIV. ${ }^{22}$ Durante o exame ginecológico, o profissional de saúde deve identificar as características do fluxo vaginal observado ao exame especular e alterações presentes, como inflamação (colpite), ulcerações, edema e eritema. ${ }^{22}$

\section{Candidíase vulvovaginal}

Os sinais característicos da candidíase vulvovaginal são eritema, fissuras vulvares, corrimento grumoso, com placas de cor branca aderidas à parede vaginal, edema vulvar, escoriações e lesões satélites, que podem se tornar pustulosas pelo intenso ato de se coçar. ${ }^{8} \mathrm{Ha}-$ bitualmente, ocorre associação de vaginite e vulvite, embora as duas condições também possam se dar de forma isolada. Clinicamente, a candidíase vulvovaginal também pode associar-se com dispareunia de 
introito vaginal e disúria externa, devida a irritação e lesões locais. ${ }^{21}$

\section{Vaginose bacteriana}

Por outro lado, na vaginose bacteriana, a mulher apresenta corrimento vaginal homogêneo e fluido, frequentemente com odor fétido. 0 desequilíbrio no microbioma vaginal tem sido identificado como uma alteração frequentemente associada com algumas IST, incluindo o HIV, complicações em cirurgias ginecológicas e gravidez (ruptura prematura de membranas, corioamnionite, prematuridade e endometrite pós-cesárea). Quando presente durante procedimentos invasivos, como curetagem uterina, biópsia de endométrio e inserção de dispositivo intrauterino (DIU), a vaginose bacteriana aumenta 0 risco de doença inflamatória pélvica. ${ }^{13} \mathrm{~A}$ condição também tem sido associada ao maior risco de infecção por papilomavírus humano (human papillomavirus, HPV) e lesões pré-cancerosas do colo uterino. ${ }^{23} \mathrm{~A}$ redução de lactobacilos comensais está associada ao $\mathrm{pH}$ vaginal aumentado e ao crescimento da microbiota anaeróbia, com a produção de aminas (putrescina, cadaverina e trimetilamina) que se tornam voláteis quando mescladas com substâncias de pH alcalino, liberando essas enzimas no ambiente e exalando odor desagradável. Isso ocorre particularmente após o coito e a menstruação (que alcalinizam o conteúdo vaginal), o que pode constituir a queixa principal da mulher. No exame especular, observam-se as paredes vaginais em sua maioria íntegras, marrons e homogêneas ao teste de Schiller, banhadas por corrimento de aspecto perolado bolhoso. ${ }^{24}$

\section{Tricomoníase}

Os sinais e sintomas da tricomoníase consistem em corrimento vaginal intenso, amarelo-esverdeado, por vezes acinzentado, bolhoso e espumoso, acompanhado de odor fétido e prurido eventual. Em quadros mais intensos, pode haver sinusiorragia (sangramento na relação sexual) e dispareunia associadas com 0 processo inflamatório. Também podem ocorrer edema vulvar e sintomas urinários, como disúria. ${ }^{25}$ A maioria dos casos de tricomoníase é assintomática, permanecendo sem diagnóstico ou tratamento. ${ }^{26}$ Embora o processo não seja inteiramente compreendido, o protozoário pode propiciar a transmissão de outros agentes infecciosos agressivos, facilitar doença inflamatória pélvica e vaginose bacteriana e, na gestação, quando não tratado, associar-se com rotura prematura das membranas. ${ }^{27}$ No exame especular, são comumente percebidas microulcerações no colo uterino, semelhantes ao aspecto de morango ou framboesa (teste de Schiller "onçoide" ou "tigroide"). A tricomoníase pode se associar à vaginose bacteriana em ambiente anaeróbio, com volatilização de aminas e odor sugestivo. ${ }^{15}$

\section{Vaginose citolítica}

Em casos de vaginose citolítica, primariamente, os sintomas são muito semelhantes aos da candidíase vulvovaginal, quando a mulher refere irritação genital associada a um corrimento de aspecto branco a branco-amarelado, em grumos, mas frequentemente com comportamento cíclico. 9 exame especular evidencia o conteúdo vaginal branco, leitoso e grumoso, aderido às paredes vaginais. $0 \mathrm{pH}$ vaginal é menor que 4,5 e 0 teste de aminas é negativo. ${ }^{18}$ Já na vaginite mista, o quadro clínico é bastante variável, a depender dos agentes envolvidos. No caso de vaginose bacteriana e candidíase, tanto pode haver a queixa predominante de corrimento com odor como de prurido genital. ${ }^{19}$

\section{Diagnóstico}

0 manejo clínico das mulheres com corrimento vaginal está apresentado na Figura 2. Para elucidação diagnóstica dos agentes causadores de fluxo vaginal, é necessária anamnese seguida de exames complementares. ${ }^{19}$

\section{Candidíase vulvovaginal}

0 diagnóstico de candidíase vulvovaginal deve ser confirmado por exames laboratoriais. 0 mais simples é o exame microscópico do conteúdo vaginal a fresco. Nesse procedimento, é colocada uma amostra de material colhido de parede vaginal em lâmina, a que se acrescenta uma a duas gotas de soro fisiológico ou hidróxido de potássio a $10 \%$ para melhor evidenciar os morfotipos de leveduras. ${ }^{28}$ Além desse exame, outro método simples e de baixo custo é a bacterioscopia de esfregaço vaginal corado pelo método de Gram. ${ }^{29}$ Nos casos de candidíase de repetição, pode ser necessária a realização de cultura para fungos (meios de Sabouraud, Nickerson ou Microstix-Candida) em amostra vaginal, com a finalidade de identificar a espécie de fungo ${ }^{30}$ Para o diagnóstico diferencial da 


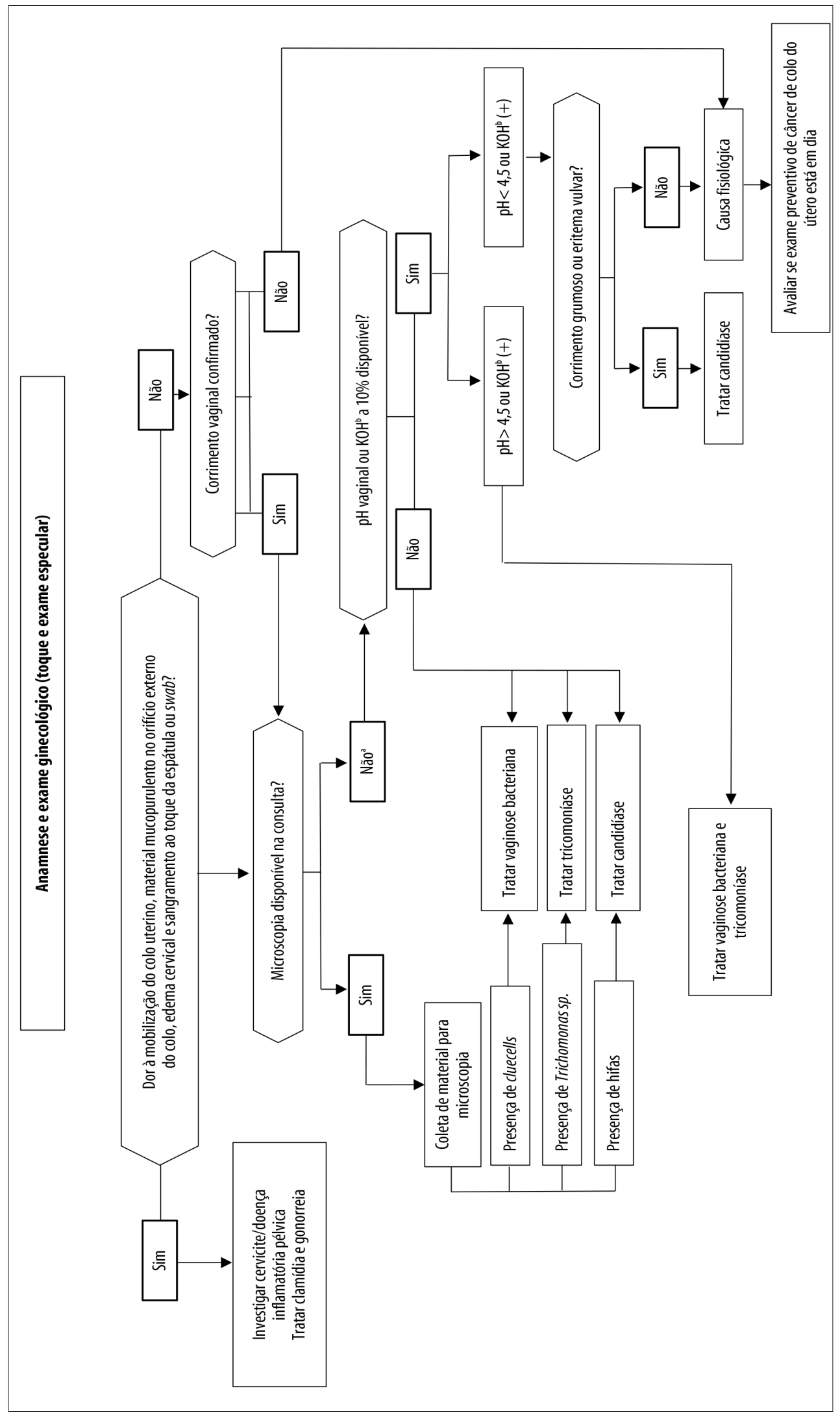


candidíase vulvovaginal recorrente, deve-se considerar líquen escleroso, vulvovestibulite, dermatite vulvar, vulvodínea, vaginite citolítica, vaginite inflamatória descamativa, formas atípicas de herpes genital e reações de hipersensibilidade. ${ }^{11}$

\section{Vaginose bacteriana}

0 diagnóstico da vaginose bacteriana é baseado nos critérios de Amsel, ${ }^{31}$ sendo necessária, para o diagnóstico, a observação de três dos quatro critérios a seguir: $\mathrm{pH}$ maior que 4,5; corrimento vaginal acinzentado e homogêneo; teste de aminas positivo; e identificação de cluecells no exame microscópico. Esse critério diagnóstico vem sendo substituído pelo escore de Nugent. ${ }^{13,32}$ Ambos os critérios podem ser associados, embora o padrão ouro seja o procedimento laboratorial de Nugent, que utiliza coloração de Gram e sistema de pontuação objetivo, indicado como evidência II-2. ${ }^{32,33}$ Esse exame atribui um escore para três morfotipos: lactobacilos, cocobacilos Gram variáveis e bacilos curvos Gram negativos. Somada a pontuação de todos os agentes, chega-se a um escore que, se for de 7 a 10, constitui diagnóstico de vaginose bacteriana. 0 escore de 4 a 6 é intermediário e de 0 a 3 é normal ${ }^{32}$ (Figura 3).

\section{Tricomoníase}

Em casos de tricomoníase, o diagnóstico laboratorial microbiológico mais comumente empregado na prática clínica é o exame a fresco do conteúdo vaginal em soro fisiológico, com observação do parasita ao microscópio. Habitualmente, visualiza-se o movimento do protozoário, que é flagelado, e um grande número de leucócitos. $0 \mathrm{pH}$ quase sempre é maior que 5,0. ${ }^{29} \mathrm{Na}$ maioria dos casos, o teste das aminas é positivo e se observam bactérias Gram-negativas na bacterioscopia, quando há testes para diagnóstico com coloração pelo método de Gram. Já o T. vaginalis é um protozoário flagelado corado pelas técnicas de Papanicolau ou de Giemsa. A cultura pode ser requisitada nos casos de difícil diagnóstico. Os meios de cultura são vários e incluem os de Diamond, Trichosel e InPouch TV. ${ }^{34} 0$ diagnóstico também pode ser realizado por meio de biologia molecular por reação em cadeia da polimerase (polymerase chain reaction, PCR), incluindo testes multiplex que conseguem detectar mais de um patógeno e permitem identificar inclusive casos assintomáticos, ${ }^{15}$ devido à sua alta sensibilidade.

0 padrão atual de teste diagnóstico para vulvovaginites depende da estrutura disponível no local de atendimento. A maioria dos diagnósticos é feita de forma empírica e com base na clínica, embora a disponibilidade de microscópio para o exame a fresco seja um importante exame complementar. Os testes moleculares direcionados ao diagnóstico de vaginose bacteriana, Candida sp. e T. vaginalis têm o potencial de melhorar a precisão do diagnóstico e reduzir 0 tempo do resultado em comparação com a cultura. ${ }^{35,36}$ Isso pode ser especialmente importante para a vaginose bacteriana, que envolve múltiplos organismos da microbiota vaginal..$^{37}$

\begin{tabular}{|c|c|c|c|c|}
\hline Escore $^{\mathrm{a}}$ & Lactobacilos & Gardnerella, Bacterioides etc. & Bacilos curvos & $\begin{array}{l}\text { Quantificação das bactérias em } \\
\text { lâmina (coloração de Gram) }\end{array}$ \\
\hline 0 & $4+$ & 0 & 0 & $\begin{array}{c}0 \\
\text { Ausência de bactérias }\end{array}$ \\
\hline 1 & $3+$ & $1+$ & $1+$ ou $2+$ & $\begin{array}{c}1+ \\
<1 \text { bactéria/campo }\end{array}$ \\
\hline 2 & $2+$ & $2+$ & $3+$ ou $4+$ & $\begin{array}{c}2+ \\
1 \text { a } 5 \text { bactérias/campo }\end{array}$ \\
\hline 3 & $1+$ & $3+$ & \multirow{2}{*}{-} & $\begin{array}{c}3+ \\
6 \text { a } 30 \text { bactérias/campo }\end{array}$ \\
\hline 4 & 0 & $4+$ & & $\begin{array}{c}4+ \\
>30 \text { bactérias/campo }\end{array}$ \\
\hline
\end{tabular}

Fonte: adaptado do Protocolo Clínico e Diretrizes Terapêuticas para Atenção Integral às Pessoas com Infecções Sexualmente Transmissíveis, 2020.22

Nota: a) Interpretação do resultado: 0 a 3 - negativo para vaginose bacteriana; 4 a 6 - microbiota alterada; 7 ou mais - vaginose bacteriana.

Figura 3 - Escore de Nugent para diagnóstico de vaginose bacteriana 


\section{Vaginose citolítica}

0 diagnóstico de vaginose citolítica deve obedecer aos seguintes critérios: corrimento branco, prurido ou ardor genital, $\mathrm{pH}$ vaginal entre 3,5 e 4,5 e exame a fresco do conteúdo vaginal sem qualquer patógeno, com identificação de grande população de bacilos médios, numerosos núcleos desnudos e detritos celulares. ${ }^{38} \mathrm{~A}$ bacterioscopia por Gram e 0 próprio exame de Papanicolau podem apresentar os mesmos achados microscópicos. ${ }^{22}$

Em casos de vaginite mista, a presença de dois microrganismos em uma mesma situação não necessariamente implica que os dois são patogênicos, em especial quando se trata de vaginose bacteriana e candidíase vulvovaginal, considerando-se que tanto a levedura como as bactérias presentes na vaginose bacteriana nem sempre são causadoras da doença. Portanto, é importante diferenciar a vaginite mista da co-ocorrência. ${ }^{18}$ No primeiro caso, os dois agentes são patogênicos, o que não ocorre necessariamente no segundo, pois a alteração do microbioma vaginal pode ser 0 agente causador da recorrência. Métodos mais avançados, como o PCR, podem levar a resultados inconclusivos, se não adequadamente interpretados.

\begin{tabular}{|c|c|c|}
\hline Condição clínica & Tratamento & Observações \\
\hline \multicolumn{3}{|l|}{ Candidíase vulvovaginal } \\
\hline Primeira opção & $\begin{array}{l}\text { Miconazol creme a } 2 \% \text { ou outros derivados imidazólicos, } \\
\text { via vaginal, um aplicador cheio, à noite ao deitar-se, por } 7 \\
\text { dias } 0 \text { U Nistatina } 100.000 \text { Ul, uma aplicação, via vaginal, à } \\
\text { noite ao deitar-se, por } 14 \text { dias }\end{array}$ & \multirow{4}{*}{$\begin{array}{l}\text { As parcerias sexuais não precisam ser tratadas, exceto as } \\
\text { sintomáticas. } \\
\text { É comum durante a gestação, podendo haver recidivas } \\
\text { pelas condições propícias do pH vaginal que se } \\
\text { estabelecem nesse período. } \\
\text { Tratamento em gestantes e lactantes: somente por } \\
\text { via vaginal. } 0 \text { tratamento oral e o uso de triazóis está } \\
\text { contraindicado. }\end{array}$} \\
\hline Segunda opção & $\begin{array}{l}\text { Fluconazol 150mg, via oral (V0), dose única OU Itraconazol } \\
100 \mathrm{mg}, 2 \text { comprimidos, V0, 2x/dia, por } 1 \text { dia }\end{array}$ & \\
\hline \multirow{2}{*}{$\begin{array}{l}\text { Candidíase vulvovaginal } \\
\text { complicada e recorrente }\end{array}$} & $\begin{array}{l}\text { Indução: fluconazol 150mg, V0, 1x/dia, nos dias 1, } 4 \text { e } 7 \text { 0U } \\
\text { Itraconazol 100mg, } 2 \text { comprimidos, V0, 2x/dia, por } 1 \text { dia } \\
\text { OU Miconazol creme vaginal tópico diário por 10-14 dias }\end{array}$ & \\
\hline & $\begin{array}{l}\text { Manutenção: fluconazol 150mg, v0, 1x/semana, por } 6 \\
\text { meses OU Miconazol creme vaginal tópico, } 2 x / \text { semana } 0 U \\
\text { Miconazol óvulo vaginal, 1x/semana, durante } 6 \text { meses }\end{array}$ & \\
\hline \multicolumn{3}{|l|}{ Vaginose bacteriana } \\
\hline $\begin{array}{l}\text { Primeira opção (incluindo } \\
\text { gestantes e lactantes) }\end{array}$ & $\begin{array}{l}\text { Metronidazol 250mg, } 2 \text { comprimidos V0, } 2 x / \text { dia, por } 7 \\
\text { dias OU Metronidazol creme, uso vaginal } 100 \mathrm{mg} / \mathrm{g} \text {, um } \\
\text { aplicador cheio via vaginal, à noite ao deitar-se, por } 5 \text { dias }\end{array}$ & \multirow{3}{*}{$\begin{array}{l}0 \text { tratamento das parcerias sexuais não está recomendado } \\
\text { Para as puérperas, recomenda-se o mesmo tratamento } \\
\text { das gestantes. }\end{array}$} \\
\hline Segunda opção & Clindamicina $300 \mathrm{mg}, \mathrm{V} 0,2 \mathrm{x} / \mathrm{dia}$, por 7 dias & \\
\hline Recorrente & $\begin{array}{l}\text { Metronidazol } 250 \mathrm{mg}, 2 \text { comprimidos V0, } 2 x / \text { dia, por } 10-14 \\
\text { dias } 0 \text { U Metronidazol creme, uso vaginal } 100 \mathrm{mg} / \mathrm{g} \text {, um } \\
\text { aplicador cheio, via vaginal, } 1 \mathrm{x} / \text { dia, por } 10 \text { dias, seguido } \\
\text { de tratamento supressivo com óvulo de ácido bórico } \\
\text { intravaginal de } 600 \mathrm{mg} \text { ao dia por } 21 \text { dias e metronidazol } \\
\text { uso vaginal } 100 \mathrm{mg} / \mathrm{g}, 2 \mathrm{2} / \mathrm{semana} \text {, por } 4-6 \text { meses }\end{array}$ & \\
\hline \multicolumn{3}{|l|}{ Tricomoníase } \\
\hline \multirow[t]{2}{*}{$\begin{array}{l}\text { Primeira opção (incluindo } \\
\text { gestantes e lactantes) }\end{array}$} & \multirow{2}{*}{$\begin{array}{l}\text { Metronidazol } 400 \mathrm{mg}, 5 \text { comprimidos, V0, dose única (dose } \\
\text { total 2g) } 0 \text { U Metronidazol 250mg, } 2 \text { comprimidos, V0, 2x/ } \\
\text { dia, por } 7 \text { dias }\end{array}$} & $\begin{array}{l}\text { As parcerias sexuais devem ser tratadas com o mesmo } \\
\text { esquema terapêutico. } 0 \text { tratamento pode aliviar os } \\
\text { sintomas de corrimento vaginal em gestantes, além de } \\
\text { prevenir infecção em recém-nascido. }\end{array}$ \\
\hline & & $\begin{array}{l}\text { Para as puérperas, recomenda-se o mesmo tratamento } \\
\text { das gestantes. }\end{array}$ \\
\hline
\end{tabular}

Fonte: adaptado do Protocolo Clínico e Diretrizes Terapêuticas para Atenção Integral às Pessoas com Infecções Sexualmente Transmissíveis, 2020.22

Figura 4 - Tratamento de candidíase vulvovaginal, vaginose bacteriana e tricomoníase 
Identificou-se que casos com critérios para vaginose bacteriana, mas que apresentam infiltrado inflamatório importante, algumas vezes sugerem um quadro de vaginite mista. ${ }^{39} \mathrm{~A}$ associação pode ser observada usando-se exame a fresco, bacterioscopia, citologia ou biologia molecular. ${ }^{40}$

\section{Tratamento}

As opções de tratamento para as vulvovaginites causadas por Candida, vaginose bacteriana e tricomoníase estão descritas na Figura 4. É importante suspender as relações sexuais para evitar novas contaminações durante o tratamento, o qual deve ser mantido no período menstrual. No tratamento com metronidazol, deve-se evitar ingestão de álcool devido ao efeito antabuse, provocado pela interação de derivados imidazólicos com álcool e caracterizado por mal-estar, náuseas, tonturas e gosto metálico na boca. ${ }^{22}$

A vaginose citolítica é tratada com uso de bicarbonato de sódio ${ }^{38} \mathrm{em}$ banhos vaginais $(15 \mathrm{~g}$ a $30 \mathrm{~g}$ de bicarbonato de sódio em $0,5 \mathrm{~L}$ de água morna), duas a três vezes por semana, por um período de duas a seis semanas. ${ }^{18} 0$ tratamento dos casos de vaginite mista é feito com terapêutica concomitante para cada um dos patógenos. No caso de candidíase e vaginose, o uso de antifúngico com metronidazol é recomendado. ${ }^{19}$

Importante ressaltar que a tricomoníase pode alterar a classe da citologia oncológica. Nos casos em que houver alterações morfológicas celulares e tricomoníase, deve-se realizar 0 tratamento e repetir a citologia após três meses, para avaliar se as alterações persistem. ${ }^{22}$ Na vaginose bacteriana recorrente, 0 triplo regime (utilização de metronidazol creme por dez dias, seguido de ácido bórico por 21 dias e manutenção com metronidazol creme duas vezes por semana, durante quatro a seis meses) parece promissor, porém requer validação com ensaio clínico randomizado e controlado. 0 papel do ácido bórico é remover o biofilme bacteriano que se forma na parede vaginal e que facilita a persistência do quadro. ${ }^{41}$

Nos casos recorrentes ou de difícil controle de candidíase vulvovaginal, devem-se investigar causas sistêmicas predisponentes, como diabetes, imunodepressão (incluindo a infecção pelo HIV) e uso de corticoides. Dentre as reações adversas raras $(0,01 \%$ a $0,1 \%)$ do uso do fluconazol, citam-se agranulocitose, leucopenia, neutropenia, trombocitopenia, anafilaxia, angioedema, hipertrigliceridemia, hipercolesterolemia, hipocalemia, toxicidade e insuficiência hepática; por isso, é importante investigar a função hepática. ${ }^{29}$

Não há indicação de rastreamento de vaginose bacteriana em mulheres assintomáticas. 0 tratamento é recomendado para todas as mulheres sintomáticas com potencial risco de complicações, como previamente à inserção de DIU, cirurgias ginecológicas e exames invasivos no trato genital. 0 tratamento deve ser simultâneo ao procedimento, não havendo razão para sua suspensão ou adiamento. ${ }^{22}$ A recorrência de vaginose bacteriana após o tratamento é comum: cerca de $15 \%$ a $30 \%$ das mulheres apresentam sintomas no período de 30 a 90 dias após a terapia com antibióticos, enquanto $70 \%$ das mulheres experimentam uma recorrência em nove meses. ${ }^{42,43}$ Alguns fatores justificam a falta de resposta terapêutica aos esquemas convencionais; dentre eles, atividade sexual frequente sem uso de preservativos, duchas vaginais, utilização de DIU, resposta imune inadequada e resistência bacteriana aos imidazólicos. Cepas de Atopobium vaginae resistentes ao metronidazol são identificadas em várias portadoras de vaginose bacteriana recorrente; contudo, esses bacilos são sensíveis à clindamicina e às cefalosporinas. ${ }^{22,41}$

A recorrência de infecção por T. vaginalis, cuja causa ainda não está clara, ocorre entre 5\% e 31\% das mulheres tratadas. É preciso avaliar o tratamento do parceiro, a exposição a novos parceiros e, por fim, a falha terapêutica. ${ }^{44} 0$ tratamento com dose única e a presença de infecção pelo HIV parecem ser os fatores mais associados com a falha terapêutica.$^{45} 0$ mecanismo molecular da resistência clínica do T. vaginalis também não está esclarecido até 0 momento. ${ }^{44}$

No seguimento das mulheres com infecções por Candida, observa-se uma frequência aumentada de recidivas na presença de alterações na imunidade celular, como nas mulheres vivendo com HIV, nas portadoras de diabetes e naquelas com infecções por Candida não albicans. 0 tratamento prolongado, combinado com mudanças comportamentais, tem sido utilizado com alguma resposta no tratamento das recidivas. ${ }^{46} 0$ diagnóstico etiológico é importante nos casos de reincidência, visando identificar a espécie presente e confirmar a infecção fúngica, dada a existência de diagnósticos diferenciais como a vulvovaginite citolítica, reações alérgicas e infecções mistas. ${ }^{47}$ 


\section{Vigilância, prevenção e controle}

0 diagnóstico de IST, diferentemente das infecções endógenas ou iatrogênicas, implica a necessidade de orientação e tratamento das parcerias sexuais. É importante avaliar a percepção da mulher quanto à existência de corrimento vaginal fisiológico e recomendar a investigação de outras IST. ${ }^{22}$

0 tratamento de parcerias sexuais, quando indicado, deve ser realizado idealmente de forma presencial, com a devida orientação, solicitação de exames para diagnóstico de outras IST e identificação, captação e tratamento das demais parcerias sexuais, buscando bloquear a cadeia de transmissão. ${ }^{22}$ No caso da tricomoníase, por se tratar de uma IST, é recomendado o tratamento das parcerias sexuais com o mesmo esquema terapêutico do caso diagnosticado. ${ }^{47}$ Nos casos de vaginose bacteriana, as parcerias sexuais não precisam ser tratadas, e, nas situações de candidíase vulvovaginal, as parcerias só precisam ser tratadas se apresentarem sintomas. Entretanto, é necessário enfatizar a importância do aconselhamento das parcerias sexuais. ${ }^{22}$

Os casos de infecções que causam corrimento vaginal não são de notificação compulsória em nível nacional, podendo a tricomoníase ser incluída, caso se considere conveniente, nas listas de notificação dos municípios e estados.

\section{Populações especiais}

\section{Gestantes}

A candidíase vulvovaginal é comum durante a gestação, podendo haver recidivas pelas condições propícias do $\mathrm{pH}$ vaginal que se estabelecem nesse período. 0 tratamento em gestantes e lactantes deve ser feito somente por via vaginal. 0 tratamento oral e o uso de triazóis está contraindicado. ${ }^{22,48}$ Embora uma revisão sistemática tenha mostrado ausência de benefício do rastreamento de vaginose bacteriana em gestantes assintomáticas, ${ }^{49}$ outros estudos demonstraram vantagem, sobretudo quando a doença se associa aos outros agentes. ${ }^{50}$ Apesar de controversas, existem sugestões para 0 tratamento de gestantes assintomáticas, sendo definido o benefício para aquelas com histórico de parto pré-termo e que apresentem comorbidades.

\section{Infecção pelo HIV}

0 tratamento deve ser realizado com os esquemas habituais para candidíase vulvovaginal, vaginose bacteriana e tricomoníase, ${ }^{22}$ mas é necessário observar a interação medicamentosa entre metronidazol e ritonavir, que pode aumentar a ocorrência de náuseas e vômitos, reduzindo a adesão aos antirretrovirais. Para evitar essa ocorrência, recomenda-se intervalo de duas horas entre as administrações de ambos os medicamentos. Também foi observado que a vaginose bacteriana propicia um conjunto de microrganismos que podem aumentar os níveis de cópias virais do HIV genital e tornar os episódios de candidíase vulvovaginal mais graves e complicados. ${ }^{51}$

\section{Contribuição dos autores}

Carvalho NS, Eleutério Junior J, Travassos AG, Santana LB e Miranda AE contribuíram com a concepção, delineamento, redação e revisão crítica do manuscrito. Todos os autores aprovaram a versão final do trabalho e são responsáveis por todos os seus aspectos, incluindo a garantia de sua precisão e integridade.

\section{Agradecimento}

Os autores agradecem aos membros do grupo técnico de especialistas responsáveis pela elaboração do PCDT para Atenção Integral às Pessoas com IST em 2020 a contribuição para a realização deste trabalho.

\section{Referências}

1. Brasil. Ministério da Saúde. Portaria MS/SCTIE $n^{0} 42$, de 5 de outubro de 2018. Torna pública a decisão de aprovar o Protocolo Clínico e Diretrizes Terapêuticas para Atenção Integral às Pessoas com Infecções Sexualmente Transmissíveis (IST), no âmbito do Sistema Único de Saúde - SUS [Internet]. Diário Oficial da

União, Brasília (DF), 2018 out 8 [citado 2020 set 4];Seção I:88. Disponível em:http://bvsms.saude.gov.br/ bvs/saudelegis/sctie/2018/prt0042_08_10_2018.html

2. Bastos LM, Passos MR, Tiburcio AS. Gestantes atendidas no setor de doenças sexualmente transmissíveis da Universidade Federal Fluminense. JBras 
Doenças SexTransm [Internet]. 2000 [citado 2020 set 8];12(2):5-12. Disponível em: http://www.dst.uff.br

3. Menezes ML. Validação do fluxograma de corrimento vaginal em gestantes [tese].Campinas, SP: Faculdade de Ciências Médicas da Universidade Estadual de Campinas; 2003. Disponível em: http://www.dst.uff.br/revista16-1-2004/6.pdf

4. Spence D, Melville C. Vaginal discharge. BMJ [Internet]. 2007Nov [cited 2020 Sep 8];335(7630):1147-51. Available from: https://doi.org/10.1136/bmj.39378.633287.80

5. Passos MR, Appolinario MA, Varella RQ. Atendimento de gestantes numa clínica de DST. JBrasDoenças SexTransm [Internet]. 2003 [citado 2020 set oito]; 15(1): 23-9. Disponível em: http://www.dst.uff.br

6. Behets FM, Ward E, Fox L, Reed R, Spruyt A, BennettL, et al. Sexually transmitted diseases are common in women attending Jamaican family planning clinics and appropriate detection tolls are lacking. Sex Transm Inf [Internet]. 1998 Jun [cited 2020 Sep 8];74(Suppl 1):S123-7. Available from: https://pubmed.ncbi.nlm.nih.gov/10023362/

7. Costello Daly C, Wangel AM, Hoffman IF, Canner JK, Lule GS, Lema VM, et al. Validation of the WHO diagnostic algorithm and development of an alternative scoring system for management of women presenting with vaginal discharge in Malawi. Sex Transm Inf [Internet]. 1998 Jun [cited 2020 Sep 8];74(Suppl 1):S50-8. Available from: https://pubmed.ncbi.nlm.nih.gov/10023354/

8. Goje 0, Munoz JL. Vulvovaginitis: find the cause to treat it. CleveClin JMed [Internet]. 2017 Mar [cited 2020 Sep 8];84(3):215-24. Available from: https://doi.org/10.3949/ccjm.84a.15163

9. Eleutério Júnior J, Ferreira RN, Freitas SF, Rodrigues FE, Moreira JC. Vaginosecitolítica: novos conceitos. Femina. 1995;23(5):423-4.

10. Holland J, Young M, Lee 0. Vulvovaginal carriage of yeasts other than Candida albicans. SexTransmInfect [Internet]. 2003 [cited 2020 Sep 8];79(3):249-50. Available from: http://dx.doi.org/10.1136/sti.79.3.249

11. Sobel JD. Vulvovaginal candidosis. Lancet [Internet]. 2007Jun [cited 2020 Sep 8];369(9577):1961-71.Available from: https:// doi.org/10.1016/S0140-6736(07)60917-9

12. Sobel JD, Wiesenfeld HC, Martens M, Danna P, Hooton TM, Rompalo A, et al. Main tenance fluconazol e therapy for recurrent vulvovaginal candidiasis. NEngl J Med [Internet]. 2004 Aug [cited 2020 Sep 8];351(9):876-83. Available from: https://doi.org/10.1056/nejmoa033114

13. Nasioudis D, Linhares IM, Ledger WJ, Witkin SS. Bacterial vaginosis: a critical analysis of current knowledge. BJOG [Internet]. 2017 Jan [cited 2020 Sep 8];124(1):61-9. Availablefrom: https://doi.org/10.1111/1471-0528.14209

14. Marconi C, El-Zein M, Ravel J, Ma B, Lima MD, Carvalho NS, et al. Characterization of the vaginal microbiome in women of reproductive age from five regions in Brazil. SexTransm Dis [Internet]. 2020 Aug [cited 2020 Sep 8];47(8):562-9. Available from: https://doi.org/10.1097/olq.0000000000001204

15. Graves KJ, Ghosh AP, Kissinger PJ, Muzny CA. Trichomonas vaginalis virus: a review of the literature. Int J STD AIDS [Internet]. $2019 \mathrm{Apr}$ [cited 2020 Sep 8];30(5):496-504. Available from: https://doi.org/10.1177/0956462418809767

16. Edwards T, Burke P, Smalley H, Hobbs G. Trichomonasvaginalis: clinical relevance, pathogenicity and diagnosis.Crit Rev Microbiol [Internet]. 2016 May [cited 2020 Sep 8];42(3):406-17. Available from: https://doi.org/10.3109/1040841x.2014.958050

17. Yang S, Zhang Y, Liu Y, Wang J, Chen S, Li S. Clinical significance and characteristics clinical differences of cytolytic vaginoses in recurrent vulvovaginitis. Gynecol Obstet Invest [Internet]. 2017 [cited 2020 Sep 8];82(2):137-43. Available from: https://doi.org/10.1159/000446945

18. Soares R, Vieira-Baptista P, Tavares S. Cytolyticvaginosis: anunder diagnosed pathology that mimics vulvovaginal candidiasis. Acta Obstet Ginecol Port [Internet]. 2017Jun [cited 2020 Sep 8];11(2):106-12.Available from: http://www. scielo.mec.pt/pdf/aogp/v11n2/v11n2a07.pdf

19. Sobel JD, Subramanian C, Foxman B, Fairfax M, Gygax SE. Mixed vaginitis-more than coinfection and with therapeutic implications.CurrInfectDis Rep [Internet]. 2013 Apr [cited 2020 Sep 8];15(2):104-8. Available from: https://doi.org/10.1007/s11908-013-0325-5

20. Eleutério Júnior J, Passos MRL, Giraldo PC, Linhares IM, Carvalho NS. Estudo em citologia em meio líquido (SurePath) da associação de Candida sp. em mulheres com diagnóstico de vaginose bacteriana. JBrasDoenças SexTransm [Internet]. 2012 [citado 
2020 set 8];24(2):122-3.Disponívelem: https:// doi.org/10.5533/DST-2177-8264-201224211

21. Centers for Disease Control and Provention - CDC. STD treatment guidelines: diseases characterized by vaginal discharge [Internet]. Washington, D.C.: CDC; 2015 [cited 2020 Sep 4]. Available from: https:// www.cdc.gov/std/tg2015/vaginal-discharge.htm

22. Ministério da Saúde (BR). Secretaria de Vigilância em Saúde. Departamento de Doenças de Condições Crônicas e Infecções Sexualmente Transmissíveis. Protocolo clínico e diretrizes terapêuticas para atenção integral às pessoas com infecções sexualmente transmissíveis (IST) [Internet]. Brasília: Ministério da Saúde; 2020 [citado 2020 set 4]. 248p. Disponível em: http://www.aids.gov.br/pt-br/ pub/2015/protocolo-clinico-e-diretrizes-terapeuticas-para-atencao-integral-pessoas-com-infeccoes

23. Gillet E, Meys JF, Verstraelen H, Bosire C, De Sutter $\mathrm{P}$, Temmerman $\mathrm{M}$, et al. Bacterial vaginosis is associated with uterine cervical human papillomavirus infection: a meta-analysis. BMC Infect Dis [Internet]. 2011 Jan [cited 2020 Sep 8];11:10. Available from: https://doi.org/10.1186/1471-2334-11-10

24. Hillier SL. Diagnostic microbiology of bacterial vaginosis. Am J Obstet Gynecol [Internet]. 1993Aug [cited 2020 Sep 8];169(2 Pt 2):455-9. Available from: https://doi.org/10.1016/0002-9378(93)90340-0

25. Sood S, Kapil A. An update on trichomonas vaginalis. Indian J Sex Transm Dis [Internet]. 2008 [cited 2020 Sep 8]; 29(1):7-14. Available from: http:/www.ijstd. org/article.asp?issn=2589-0557;year $=2008$; volume $=29 ;$ issue $=1$ spage $=7$;epage $=14$; aulast $=$ Sood

26. Allsworth JE, RatnerJA, Peipert JF. Trichomoniasis and other sexually transmitted infections: results from the 2001-2004 National Health and Nutrition Examination Surveys. Sex Transm Dis [Internet]. 2009 Dec [cited 2020 Sep 8];36(12):738-44. Available from: https://doi.org/10.1097/olq.0b013e3181b38a4b

27. Mann JR, McDermott S, Gill T. Sexually transmitted infection is associated with increased risk of preterm birth in South Carolina women insured by Medicaid. J Matern Fetal Neonatal Med [Internet]. 2010 Jun [cited 2020 Sep 8];23(6):563-8. Available from: https://doi.org/10.3109/14767050903214574

28. Hainer BL, Gibson MV. Vaginitis: diagnosis and treatment. Am Fam Physician [Internet]. $2011 \mathrm{Apr}$ [cited 2020 Sep 8];83(7):807-15. Available from: https://www.aafp.org/afp/2011/0401/p807.html
29. Paladine HL, Desai UA. Vaginitis: diagnosis and treatment. Am Fam Physician [Internet].2018 Mar [cited 2020 Sep 8];97(5):321-9. Available from: https://www.aafp.org/afp/2018/0301/p321.html

30. Pappas PG, Kauffman CA, Andes D, Benjamin DK Jr, Calandra TF, Edwards JE Jr, et al. Clinical practice guidelines for the management of candidiasis: 2009 update by the Infectious Diseases Society of America. Clin Infect Dis [Internet]. 2009 Mar [cited 2020 Sep 8];48(5):503-35. Available from: https://doi.org/10.1086/596757

31. Amsel R, Totten PA, Spiegel CA, Chen KC, Eschenbach D, Holmes KK. Nonspecific vaginitis: diagnostic criteria and microbial and epidemiologic associations. Am J Med [Internet]. $1983 \mathrm{Jan}$ [cited 2020 Sep 8];74(1):14-22. Available from: https://doi.org/10.1016/0002-9343(83)91112-9

32. Nugent RP, Krohn MA, Hillier SL. Realibility of diagnosing bacterial vaginosis in improved by a standardized method of gram stain interpretation. J Clin Microbiol [Internet]. 1991 Feb [cited 2020 sep 8];29(2):297-301. Available from: https://www. ncbi.nlm.nih.gov/pmc/articles/PMC269757/

33. Van SchalkwykJ, Yudin MH, Infectious Diseases Committee. Vulvovaginitis: screening for and management of trichomoniasis, vulvovaginal candidiasis, and bacterial vaginosis. J Obstet Gynaecol Can [Internet]. 2015 Mar [cited 2020 Sep 8];37(3):266-74. Available from: https://doi.org/10.1016/s1701-2163(15)30316-9

34. Haefner HK. Current evaluation and management of vulvovaginitis. Clin Obstet Gynecol [Internet]. 1999 Jun [cited 2020 Sep 8];42(2):184-95. Available from: https://doi.org/10.1097/00003081-199906000-00004

35. Kusters JG, Reuland EA, Bouter S, Koenig P, Dorigo-Zetsma JW. A multiplex real-time PCR assay for routine diagnosis of bacterial vaginosis. Eur J Clin Microbiol Infect Dis [Internet]. 2015 Sep [cited 2020 Sep 8];34(9):1779-85. Available from: https://doi.org/10.1007/s10096-015-2412-Z

36. Schwebke JR, Gaydos CA, Nyirjesy P, Paradis S, Kodsi S, Cooper CK. Diagnostic performance of a molecular test versus clinician assessment of vaginitis. J Clin Microbiol [Internet]. 2018 May [cited 2020 Sep 8];56(6):e00252-18. Available from: https://dx.doi.org/10.1128\%2FJCM.00252-18

37. Srinivasan S, Fredricks DN. The human vaginal bacterial biota and bacterial vaginosis. Interdiscip Perspect Infect Dis [Internet]. 2008 
Feb [cited 2020 Sep 8]:750479. Available from: https://dx.doi.org/10.1155\%2F2008\%2F750479

38. Cibley LJ, Cibley LJ. Cytolyticvaginosis. Am J Obstet Gynecol [Internet]. 1991 0ct [cited 2020 Sep 8];165(4 Pt 2):1245-9. Available from: https:// doi.org/10.1016/S0002-9378(12)90736-X

39. Eleuterio Júnior J,Eleuterio RMN, Martins LA, Giraldo PC, Gonçalves AKS. Inflammatory cells in liquid-based cytology smears classified as bacterial vaginosis.Diagn Cytopathol [Internet]. 2017 Dec [cited 2020 Sep 8]; 45(12):1100-04. Available from: https://doi.org/10.1002/dc.23830

40. Eleutério Júnior J, Eleuterio RMN, Valente ABGV, Queiroz FS, Gonçalves AKS, Giraldo PC.Comparison of BD affirm VPIII with gram and liquid-based cytology for diagnosis of bacterial vaginoses, candidiasis and Trichomonas. Clin Exp Obstet Gynecol [Internet]. 2019 Mar [cited 2020 Sep 8];66(1):32-5.Available from: https://doi.org/10.1309/AJCP7TBN5VZUGLZU

41. Machado D, Castro J, Palmeira-de-0liveira A, Martinez-de-Oliveira J, Cerca N, et al. Bacterial vaginosis biofilms: challenges to current therapies and emerging solutions. Front Microbiol [Internet].2016 Jan [cited 2020 Sep 8];6:1528-41. Available from: https://doi.org/10.3389/fmicb.2015.01528

42. Bradshaw CS, Morton AN, Hocking J, Garland SM, Morris MB, Moss LM, et al. High recurrence rates of bacterial vaginosis over the course of 12 months after oral metronidazol e therapy and factors associated with recurrence. J Infect Dis [Internet]. 2006 Jun [cited 2020 Sep 8];193(11):1478-86. Available from: https://doi.org/10.1086/503780

43. Peterman TA, Tian LH, Metcalf CA, Satterwhite CL, Malotte CK, DeAugustine N, et al. High incidence of new sexually transmitted infections in the year following a sexually transmitted infection: a case for rescreening. Ann Intern Med [Internet]. 2006 0ct [cited 2020 Sep 8];145(8):564-72. Available from: https:// doi.org/10.7326/0003-4819-145-8-200610170-00005
44. Kissinger P. Trichomonasvaginalis: a review of epidemiologic, clinical and treatment issues. BMC Infect Dis [Internet]. 2015 Aug [cited 2020 Sep 8];15:307. Available from: https://doi.org/10.1186/s12879-015-1055-0

45. Kissinger P, Secor WE, Leichliter JS, Clark RA, Schmidt N, Curtin E, et al. Early repeated infections with Trichomonasvaginalis among HIV-positive and HIV-negative women. Clin Infect Dis [Internet]. 2008 Apr [cited 2020 Sep 8];46(7):994-9. Available from: https://dx.doi.org/10.1086\%2F529149

46. Blostein F, Levin-Sparenberg E, Wagner J, Foxman B. Recurrent vulvovaginal candidiasis. Ann Epidemiol [Internet]. 2017Sep [cited 2020 Sep 8];27(9):575-82.Available from: https:// doi.org/10.1016/j.annepidem.2017.08.010

47. Sobel JD. Genital candidiasis.Medicine [Internet]. 2014Jun [cited 2020 Sep 8];42(7):364-8.Available from: https://doi.org/10.1016/j.mpmed.2014.04.006

48. Wendel KA, Workowski KA. Trichomoniasis: challenges to appropriate management.Clin Infect Dis [Internet]. 2007 Apr [cited 2020 Sep 8];44(Suppl 3):S123-9. Available from: https://doi.org/10.1086/511425

49. Brocklehurst P, Gordon A, Heatley E, Milan SJ. Antibiotics for treating bacterial vaginosis in pregnancy. Cochrane Database Syst Rev [Internet]. 2013 Jan [cited 2020 Sep 8];1:CD000262. Available from: https://doi.org/10.1002/14651858.cd000262.pub4

50. Foxman B, Wen A, Srinivasan U, Goldberg D, Marrs CF, Owen J, et al. Mycoplasma, bacterial vaginosis-associated bacteria BVAB3, race, and risk of preterm birth in a high-risk cohort.Am J Obstet Gynecol [Internet]. 2014 Mar [cited 2020 Sep 8];210(3):226.e1-7. Available from: https://doi.org/10.1016/j.ajog.2013.10.003

51. Reda S, Gonçalves FA, Mazepa MM, Carvalho NS. Women infected with HIV and the impact of associated sexually transmitted infections. Int J Gynaecol Obstet [Internet]. 2018Aug [cited 2020 Sep 8];142(2):143-7. Available from: https://doi.org/10.1002/ijgo.12507 


\section{Abstract}

The topic of vaginal discharge is one of the chapters of the Clinical Protocol and Therapeutic Guidelines for Comprehensive Care for People with Sexually Transmitted Infections, published by the Brazilian Ministry of Health in 2020. The chapter has been developed based on scientific evidence and validated in discussions with specialists. This article presents epidemiological and clinical aspects related to vaginal discharge conditions, as well as guidelines for bealth service managers and health professionals about screening, diagnosing and treating these conditions, which are one of the main complaints among women seeking health services, and which may be caused by infectious or non-infectious factors. In addition, information is presented on strategies for surveillance, prevention and control actions, in order to promote knowledge of the problem and provision of quality care and effective treatment.

Keywords: Vaginitis; Candidiasis, Vulvovaginal; Vaginosis, Bacterial; Trichomonas Infections; Sexually Transmitted Diseases.

\section{Resumen}

El tema del flujo vaginal es uno de los capítulos del Protocolo Clínico y Directrices Terapéuticas para la Atención Integral a las Personas con Infecciones de Transmisión Sexual, publicado por el Ministerio de Salud de Brasil en 2020. El documento fue desarrollado en base a evidencia científica y validado en discusiones con especialistas. En este artículo se presentan aspectos epidemiológicos y clínicos relacionados a las situaciones de flujo vaginal, así como pautas para gestores y profesionales de la salud en el cribado, diagnóstico y tratamiento de esas complicaciones, que son una de las principales quejas entre las mujeres que buscan servicios de salud y que pueden ser causadas por factores infecciosos o no infecciosos. Además, se presenta información sobre estrategias para acciones de vigilancia, prevención y control, con el fin de promover la comprensión del problema y la oferta de asistencia de calidad y tratamiento eficaz.

Palabras clave: Vaginitis; Candidiasis Vulvovaginal; Vaginosis Bacteriana; Tricomoniasis; Enfermedades de Trasmisión Sexual.

Recebido em 22/07/2020

Aprovado em 30/09/2020 